\title{
INFLUENCE OF THE HISTOCOMPATIBILITY SYSTEM ON REPRODUCTIVE EFFICIENCY OF TURKEYS
}

\author{
F. L. CHERMS \\ Department of Poultry Science, University of Wisconsin, \\ Madison, Wisconsin, U.S.A.
}

(Received 11th December 1968)

The histocompatibility system (h.s.) in chickens, ascribed originally to the B blood group locus (Schierman \& Nordskog, 1961) and additionally to the C. blood group locus (Schierman \& Nordskog, 1965) and the W sex chromosome (Bacon \& Craig, 1966; Gilmour, 1967), may be even more complicated since Hála (1968) reported on two inbred lines that differed by as many as ten histocompatibility loci. It is evident that certain combinations of alleles within the $B$ locus are responsible for improved survival and reproductive efficiency and led Nordskog (1964) to state that "the cumulative evidence leads to one rather consistent finding: that B locus polymorphisms have adaptive value." $\mathrm{He}$ further pointed out that the advantages of some blood groups may be the result of linkages with other genes influencing fitness and that these would best be studied in a population in equilibrium (non-inbreds).

Most of the studies on the relationship of the B locus to other traits in chickens have been conducted using inbred lines. This report presents the results of a study in which the influence of the h.s. upon reproductive efficiency, as measured by fertility and hatchability, was determined in non-inbred turkeys.

Standard blood typing procedures have been used by workers in this area for identification of allelic combinations. Allen (1962) found that random bred populations present technical difficulties in the development of antigens and thus in the accurate identification of blood group genotypes. This procedure can be circumvented in the identification of the h.s. of non-inbreds by the presence or absence of splenomegaly following the administration of adult cells to embryos (Solomon \& Tucker, 1963).

Splenomegalic response in embryos measured 5 days after a single i.v. injection, on the 20th day of incubation, of $0.25 \mathrm{ml}$ citrated blood from the embryos' sire was used to determine the compatibility status of mates in a line of Broad White turkeys. Thirty-six single male matings, each composed of six non-related females, were examined. Since the basis of the splenomegalic response is the recognition by the adult blood of histocompatible alleles different from its own, three different classes of matings are possible. In one instance the female, and thus her embryos, would carry the same alleles as the sire, resulting in no splenomegaly, and the mating would be classified as compatible. If the hen's alleles differ entirely from the sire's, then all embryos would give a splenomegalic response and the mating considered as incompatible. A third class exists in which a portion of the hen's alleles are the same as the sire's and 
the remainder is different. In this instance, splenomegaly will occur in some embryos of such a mating and not in others, and the mating is classified as segregating. A mating was not considered as classified until a minimum of five embryos was examined for each mating. In the segregating matings, a minimum of two embryos of each type was necessary for classification.

Of the 197 females that were successfully tested, $46(23.4 \%)$ were in the compatible class, $57(28.9 \%)$ were incompatible, and $94(47.7 \%)$ were classified as segregating. It is interesting to note that on the assumption of two alleles at each histocompatibility locus and using the table presented by Hála (1968), the $23.4 \%$ level of compatible mating indicates that this population differs at five histocompatibility loci.

Of the thirty-six matings successfully tested, only twenty-seven provided reproductive data over a 16-week period of egg production. Nine of the thirtysix matings were not included because the males ceased semen production

TABLE 1

FERTILITY, HATCHABILITY OF FERTILE EGGS (H.F.E.) AND HATCH OF ALL EGGS SET (H/S) FOR MATINGS GLASSIFIED AS TO GOMPATIBILITY STATUS

\begin{tabular}{|c|c|c|c|c|}
\hline $\begin{array}{l}\text { Compatibility } \\
\text { classification }\end{array}$ & $\begin{array}{l}\text { No. } \\
\text { hens }\end{array}$ & $\begin{array}{c}\% \\
\text { fertile }\end{array}$ & $\begin{array}{c}\% \\
H . F . E .\end{array}$ & $\%$ \\
\hline $\begin{array}{l}\text { Compatible } \\
\text { Incompatible } \\
\text { Segregating }\end{array}$ & $\begin{array}{l}34 \\
46 \\
72\end{array}$ & $\begin{array}{l}92 \cdot 1^{\mathrm{ab} *} \\
91 \cdot 2^{\mathrm{b}} \\
93 \cdot 4^{\mathrm{a}}\end{array}$ & $\begin{array}{l}74 \cdot 7^{\mathrm{b}} \\
73 \cdot 0^{\mathrm{b}} \\
79 \cdot 7^{\mathrm{a}}\end{array}$ & $\begin{array}{l}69 \cdot 1^{\mathrm{b}} \\
65 \cdot 8^{\mathrm{c}} \\
75 \cdot 3^{\mathrm{a}}\end{array}$ \\
\hline
\end{tabular}

* Duncan's new multiple-range test (Steel \& Torrie, 1960) at the $5 \%$ level of significance in which any two values, within a given trait, with the same superscript (a,b or c) are not significantly different.

sometime before the end of the 16-week period. Data for fertility, hatch of fertile eggs, and hatch of all eggs set $(\mathrm{H} / \mathrm{S})$ were transformed to the arc-sine and analysed by analysis of variance procedures (Steel \& Torrie, 1960) with the main effects being the four 4-week periods ( 1 to 4 weeks, 5 to 8 weeks, 9 to 12 weeks, and 13 to 16 weeks) of reproductive data and compatibility classification. Significant differences between main effects were located by applying Duncan's new multiple-range test (Steel \& Torrie, 1960). Since the period effect and the period-compatibility interaction proved to be negligible, the data is presented here by compatibility classification. The data in Table 1 show not only the number of hens in each class but also the average values of the three trials. In each instance, the segregating class is significantly greater than the incompatible class. Even though the compatible class is numerically higher than the incompatible class for all three traits, only in the instance of $\mathrm{H} / \mathrm{S}$ is this difference significant.

The case of the segregating class is most interesting in that all matings in a population would be of this type in either a three-way cross in which two of the parental lines carried the same genetic factors in the h.s. or in a backcross and may account for the improvement noted in certain of these types of crosses. 
A simplified example of this, using two alleles at one locus (designated 1 and 2), would be a case in which the sire was of a $2 / 2$ genotype and the dam came from a cross of $1 / 1$ and $2 / 2$ parents. The progeny from such a three-way cross would be of $1 / 2$ and 2/2 genotypes and when tested with the blood of the male parent, $2 / 2$ would give no splenomegaly while the $1 / 2$ progeny would give such a response. Thus, all matings in such a population would be classed as segregating. Indeed, the development of lines that will produce this type of combination is warranted and will be studied further.

This study was conducted at the Nicholas Turkey Breeding Farms, Inc., Sonoma, California.

\section{REFERENCES}

Allen, C. P. (1962) The effect of parental B locus genotypes on multiple cross performance in chickens. Ann. N.Y. Acad. Sci. 97, 184.

Bacon, L. D. \& CraIG, J. V. (1966) Evidence for a histocompatibility locus on the W chromosome in chickens. Poultry Sci. 45, 1066.

GilmouR, D. G. (1967) Histocompatibility antigen in the heterogametic sex in the chicken. Transplantation, 4, 699 .

HÁLA, K. (1968) Determination of the number of histocompatibility loci in inbred lines of chickens. In: Advance in Transplantation. Williams \& Wilkins, Baltimore.

Nordskog, A. W. (1964) Poultry immunogenetics. Wld's Poult. Sci. J. 20, 183.

Schierman, L. W. \& Nordskog, A. W. (1961) Relationship of blood type to histocompatibility in chickens. Science, N.X. 134, 1008.

Schierman, L. W. \& Nordskog, A. W. (1965) Evidence for a second blood group-histocompatibility system in chickens. Transplantation, $3,44$.

Solomon, J. B. \& Tucker, D. F. (1963) Immunological attack by adult cells in the developing chick embryo: influence of the vascularity of the host spleen and of homograft rejection by the embryo on splenomegaly. F. Embryol. exp. Morph. 2, 119.

Steel, R. G. D. \& Torrie, J. H. (1960) Principles and procedures of statistics. McGraw-Hill, New York. 